\title{
A Descriptive Analysis of the Metacognitive Reading Strategies Employed by EFL College Students in Kuwait
}

\author{
Sulaiman Alrabah ${ }^{1} \&$ Shu-hua $\mathrm{Wu}^{1}$ \\ ${ }^{1}$ Language Center, College of Business Studies, Public Authority for Applied Education and Training, Kuwait \\ Correspondence: Shu-hua Wu, Language Center, College of Business Studies, Public Authority for Applied \\ Education and Training, Kuwait. E-mail:wu104ohio@yahoo.com.tw
}

Received: September 17, 2018 Accepted: October 12, 2018 Online Published: December 27, 2018

doi:10.5539/ijel.v9n1p25 URL: https://doi.org/10.5539/ijel.v9n1p25

\begin{abstract}
The study measured the awareness and use of metacognitive reading strategies among English as a foreign language (EFL) students at a medical college in Kuwait. The college offers a four-year Bachelor of Science in Nursing (BSN) and a two-year Associate Degree in Nursing (ADN). Data collection involved distributing the Metacognitive Awareness of Reading Strategy Inventory (MARSI) online through Google Forms to a sample of 80 students (Mokhtari \& Reichard, 2002). Data were analyzed for strategy use, variations in strategy use between the BSN and ADN students, and the most and the least frequently-used strategies by the participating students. Microsoft Excel software generated the means, percentages, rankings, and standard deviations of strategy use. Findings indicated that the participating students were overall highly aware of metacognitive reading strategies. Moreover, the results showed that while the participating students were high users of problem-solving and global strategies, they were medium users of support strategies. The results also indicated that years of studying English showed a possible impact on the variations in strategy use between the participating students at the BSN and ADN programs. Finally, the analysis revealed that while the most frequently-used strategies among the participants were problem-solving strategies followed by global strategies, the least frequently-used strategies were support strategies. Implications for pedagogy included the need for English teachers to first identify their students' awareness of metacognitive reading strategies. Second, English teachers can implement evidence-based instruction to maximize the use of students' metacognitive reading strategies.
\end{abstract}

Keywords: metacognitive awareness of reading strategies, English as a foreign language (EFL), L2 Reading, reading comprehension, reading proficiency, evidence-based practice, reading strategy instruction

\section{Introduction}

Reading is one of the most crucial skills to learn in a foreign language. To help EFL students become efficient readers, a number of researchers (e.g., Friesen \& Haigh, 2018) recommended instruction in metacognitive reading strategies to enhance second language reading comprehension. Pani (2004) defined meta-cognitive reading strategies as "the mental operations involved when readers approach a text effectively to make sense of what they read" (p. 355). Mokhtari and Reichard (2002) classified metacognitive reading strategies as global, problem-solving, and support strategies. Global strategies include planning, monitoring, and evaluating what one has read. Problem-solving strategies are aimed at solving problems when the text becomes difficult to read. Support reading strategies signify the use of outside reference materials such as looking up unknown words in dictionaries. One of the most consistent findings in studies of metacognitive awareness of reading strategies is that good readers selectively and consciously employ a bigger variety of reading strategies and use them more frequently than poor readers (e.g., Magno, 2010; Park, 2015). EFL reading researchers have, moreover, suggested that reading comprehension difficulties can rise from low decoding skills due to lack of proficiency rather than from lack of strategy awareness. On the one hand, learners who have low proficiency have not yet developed beyond the simple decoding of texts, word-recognition, and translation using dictionaries. On the other hand, learners who have reached higher proficiency levels have entered an advanced stage in which they can employ a variety of metacognitive reading strategies at their disposal to support their reading comprehension performance. Reading strategy studies in EFL settings also reported that both good and poor readers have been shown to use similar reading strategies, but they differ in the frequency and variety of strategy use as well as 
good readers' ability to draw on a variety of strategies in a coherent manner to process reading texts (e.g., Al-Mekhlafi, 2018; Al-Sohbani, 2013; Boyraz \& Altinsoy, 2017; Endley, 2016). Therefore, regardless of proficiency level, good readers are generally aware of strategies and use them efficiently, but less successful, or poor, readers are prevented from drawing on strategic knowledge by their limited proficiency in the L2 (Malcolm, 2009).

Due to the fact that no studies were published so far on the use of metacognitive reading strategies by EFL students in Kuwait, the present study was conducted to investigate the metacognitive reading strategies employed by a sample of 80 students at a medical college Kuwait. The MARSI was used by the researchers to identify the types of metacognitive reading strategies and to measure the frequency with which they were used by the participating students. The purpose of the study was, therefore, three-fold: (1) to discover participants' awareness and use of different types of metacognitive reading strategies, (2) to identify the variations in strategy us between the BSN and ADN students, and (3) to distinguish between the most and the least frequently-used metacognitive reading strategies by the participating students. The study was conducted in search for answers for the following research questions:

1) What were the types of metacognitive reading strategies employed by the participating students?

2) What were the variations in strategy use between the BSN and ADN students?

3) What were the most and the least frequently-used metacognitive reading strategies by the students?

\section{Review of the Literature}

This review was divided into three sections. The first section described the learning context of the present study. The second section presented research studies on reading strategy use in EFL contexts. Finally, the third section dealt with studies that investigated the relationship between proficiency and strategy use.

\subsection{Context of the Study}

Increasing demands on the medical profession worldwide have been made for nursing professionals to have high levels of English proficiency in order to perform their tasks effectively in their workplaces (Ferguson, 2013). The present study was conducted in the learning context of the College of Nursing in Kuwait where English is used as the medium of instruction (EMI) in all major courses. EMI means that required textbooks and term tests as well as the language of instruction are delivered in English. In the College of Nursing in Kuwait, the amounts of required reading assignments in English average more than a hundred pages of medical texts each week. Therefore, the mission of the English department was to help students reach high proficiency in English. The courses offered by the English department were designed to reinforce the medical content of major courses to improve students' reading competence in English. Another feature of the context of the College of Nursing in Kuwait is the two-degree programs in which the Bachelor of Science in Nursing (BSN) students spend four years, and the Associate Degree in Nursing (ADN) in which the students spend two years to earn their diplomas. Therefore, the aim of the present study was to discover the metacognitive reading strategies among the participants in order to add to the current knowledge-base an understanding of the awareness and use of metacognitive reading strategies among college EFL students in Kuwait.

\subsection{Studies of Arabic EFL Learners}

Recent metacognitive reading strategy investigations in settings such as Oman, Bahrain, UAE, Yemen, and Saudi Arabia (e.g., Al-Mekhlafi, 2018; Al-Sohbani, 2013; Endley, 2016; Malcom, 2009; Meniado, 2016) have suggested that even though good EFL readers use strategies more frequently than poor readers, they all report similar metacognitive awareness of reading strategies, regardless of language proficiency. Al-Mekhlafi (2018), Endley (2016), and Malcom (2009) conducted their studies in EMI university settings in Oman, UAE, and Bahrain. Being a student at an EMI university adds demands to develop overall proficiency in English to be able to follow routine lectures, comprehend assigned readings, and perform well in exams. This "swim" or "sink" environment might impact students' awareness of metacognitive reading strategies. Al-Mekhlafi (2018), for example, investigated Omani learners' metacognitive awareness of reading strategies in relation to gender and proficiency. The students were admitted to university and took an English placement test which placed them at elementary, intermediate, and advanced levels of proficiency. No significant differences in strategy use were found among 74 university students of different proficiency levels. Moreover, Malcom (2009) investigated the reading strategy awareness of 160 students of varying proficiency levels at a medical university in Bahrain. Using the "Survey of Reading Strategies" (SORS), which included items related to translation strategies, Malcom found that the low proficiency students were using translation from their L1 (Arabic) as a reading strategy. The low proficiency students were translating more than the high proficiency students while the high 
profiency students were using more metacognitive strategies than the low proficiency students. Malcom explained students' shift from translation to metacognition by referring to "excessive" reading demands on medical students. Because of the demands of the EMI university, the students were pushed to rapidly develop in their reading ability from simple decoding and translation to more effective metacognitive strategies such as planning, monitoring, and evaluating their reading assignments throughout their study program. Furthermore, Endley (2016) utilized a think-aloud protocol followed by a semi-structured interview to investigate the reading strategies of 12 EFL students at an EMI university in the United Arab Emirates. Endley found that both high and low proficiency Arabic-speaking EFL learners preferred problem-solving and support strategies over global strategies to cope with their reading comprehension problems.

Within non-EMI universities, a number of studies were conducted that reached a different set of conclusions about EFL students' awareness and use of metacognitive reading strategies. Meniado (2016), for example, conducted a study at a technical university EFL setting in Yanbu, Saudi Arabia. He investigated whether there were any relationships between reading motivation, metacognitive readings strategies, and reading comprehension performance. $60 \mathrm{EFL}$ students who were randomly selected for the study were found to be moderate users of metacognitive reading strategies when reading academic texts. Problem-solving strategies were found to be the most frequently used among students. The participants were highly motivated to read but they preferred comic books and fun materials as opposed to academic texts. However, a positive correlation existed between students' reading strategies and their reading motivations. Nevertheless, they all performed below average on the reading comprehension test. Moreover, Al-Sohbani (2014) explored the reading strategy use of Yemeni EFL university students and aimed to discover whether gender had a role to play in strategy use. A total of 100 English majors (70 females and 30 males) completed the Survey of Reading Strategies (SORS). Al-Sohbani reported that problem-solving strategies were the Yemeni students' most preferred strategies closely followed by global and support strategies. The results revealed that both male and female students had a high degree of awareness of reading strategy use. As far as the correlation between learners' marks in reading skills exams and their overall metacognitive reading strategy use, Al-Sohbani found significant correlations between learners' scores and learners' global and problem-solving strategies but "no correlation was found between learners' scores in reading skill and their use of support strategies" (p. 130).

From a pedagogical perspective, there is wide appeal for the notion of explicit instruction in reading strategy use among EFL learners. Pedagogical intervention in English reading classes can presumably help poor readers' strategy use, empowering them to deal autonomously with the academic English texts they will read later. However, analysis of the data collected for a study by Mehrdad, Ahghar, and Ahghar (2012) determined that instruction in metacognitive reading strategies in EFL settings did not have positive effects on EFL students' reading comprehension performance. Moreover, a study conducted by Pei (2014) found that instruction in metacognitive reading strategies has not resulted in improved results in better reading comprehension performance for EFL students in China. Due to the fact that there are multiple factors influencing the "complex" world of classroom teaching (Mintz \& Yun, 1999), it is difficult to offer a definitive answer to the question of whether or not reading strategy instruction can improve reading comprehension among EFL learners.

\subsection{Proficiency and Strategy Use}

Studies that have investigated the relationship between a learner's proficiency in English and her/his reading strategy use have consistently reported that successful readers are metacognitively aware and tend to utilize sophisticated strategies to deal with texts. Conversely, poor readers are not highly aware and they do not employ enough reading strategies to process texts and, therefore, tend to have low reading comprehension (Huang \& Nisbet, 2014; Kuru Gönen, 2014; Park, 2015). Among researchers who investigated the relationship between proficiency and strategy use were Huang and Nisbet (2014) who distributed Mokhtari and Sheorey's (2002) Survey of Reading Strategies (SORS) among 121 adult ESL students enrolled in ESL classes at the adult learning center to measure their strategy use (i.e., global, problem-solving, and support strategies). Based on regression analysis of survey results and student proficiency scores, Huang and Nisbet (2014) reported two findings. First, problem-solving strategies and support strategies were found to be most predictive of students' reading proficiency scores than global strategies. Second, although the relationship between reading proficiency levels and strategy use were not statistically significant, a clear pattern of strategy use was found among the students in which high intermediate learners used the most strategies and advanced learners used the least strategies. These findings lend support to the premise that there exists a strong relationship between a student's proficiency level and her/his patterns of strategy use. Moreover, Park (2015) investigated the relationships between reading motivation, proficiency, and strategy use. Park targeted a group of 57 Korean students in an English reading course at a Korean university. To measure their reading proficiency, a reading comprehension test was 
administered at the data collection stage. A survey instrument was used by the researcher to measure students' motivation to read in English, and another survey was used to measure their reading strategy use. Park reported that students' performance on the reading comprehension test was positively related to their reported reading strategy use. Data analysis also revealed that, in contrast to the least proficient students, the more proficient students utilized more reading strategies more frequently than the less proficient students to enhance their reading comprehension. However, in a study on 65 ESP students in a Turkish university, Kuru Gönen (2014) investigated the relationship between reading strategy use, reading proficiency, and achievement. Regression analyses were conducted on the relationship between the students' scores on a reading strategy survey and their scores on achievement and reading proficiency tests. Kuru Gönen found that the ESP students used a variety of reading strategies while reading academic materials. Nevertheless, correlation analyses revealed weak relationships between students' reading strategy use and their performance on both achievement and reading proficiency tests. This indicated that the link between reading proficiency, achievement, and strategy use was not consistent among ESP students. So even though some of the students were proficient, they did not readily employ effective reading strategies to deal with academic texts. Based on this finding, the researcher recommended instruction on how to use more effective reading strategies for ESP students to be able to efficiently handle ESP academic reading materials. Consequently, a strong link was established by these studies between reading strategies and proficiency. Highly proficient readers apparently utilize a wider range of strategies than readers with low proficiency. Additionally, the frequency with which successful readers use strategies appears to be higher than their less proficient counterparts.

Unfortunately, the research relating proficiency to reading strategy use has maintained a two-dimensional outlook to successful versus poor readers. Most of these studies have, in effect, ignored the potential variability among learners as they develop as readers into a binary description of successful vs. poor readers. This outlook has, moreover, neglected that individual learners, under normal classroom conditions, are expected to progress and go through several stages of development until they reach overall proficiency in the L2 (Pienemann, 2005). Al-Mekhlafi (2018), Endley (2016), and Malcom (2009) have found that when proficiency increases, a learner's processing of texts shifts from simple decoding, word-recognition, and translation to more sophisticated strategies where readers plan, monitor, and evaluate reading texts. Thus, the present study aimed to explore the variations in strategy use between the BSN and ADN participants.

In conclusion, studies of metacognitive reading strategy use in EFL and EMI contexts suggested that there are multiple degrees of awareness and use of metacognitive reading strategies among EFL students. It is safe to assume that high awareness and use of metacognitive reading strategies can help EFL learners improve their reading comprehension performance. Because of the importance of enhancing the reading skills of EFL students in Kuwait, there was a need to conduct the present study to discover the strategies used by a sample of EFL students at the College of Nursing in Kuwait. Thus, the present study was conducted to achieve three aims. First, there was a need to identify the metacognitive reading strategies of students at the College of Nursing in Kuwait. Second, there was a need to investigate the variation between the two groups of BSN and ADN students in strategy use. Third, the study targeted the most and the least frequently-used reading strategy choices by the participants.

\section{Methodology}

The study was implemented in two stages. The first stage consisted of data collection in administering the Metacognitive Awareness of Reading Strategies Inventory (MARSI) by Mokhtari and Reichard (2002). The instrument was used for measuring the participants' self-reported responses on three subscales of metacognitive reading strategies including global, problem-solving, and support strategies. Mobile technology provided the advantage for the researchers of entering the survey into Google Forms and asking students to read and sign the "consent forms" required to participate in the study. The second stage consisted of data analysis which utilized Excel software to generate the means, standard deviations, and ranks of the participating students' strategy use. Data display consisted of tables 1,2 , and 3 to show the trends and variations in metacognitive reading strategy use among the participants.

\subsection{Sampling and Participants}

The researchers investigated the metacognitive reading strategies of EFL students at the College of Nursing in Kuwait which has two different degree programs: (1) a four-year Bachelor of Science in Nursing (BSN), and (2) a two-year Associate Degree in Nursing (ADN). "Convenience sampling" (Patton, 2015) was used to gain access to the participants from both programs who were taking four English for Specific Purposes (ESP) classes during Spring and Summer semesters from February to July, 2018. A total of 83 students volunteered from the four 
"intact" classes which had approximately 20 students each. Solicitation letters explained the purpose of the research along with assurances of protecting the confidentiality and anonymity of each participant. An informed consent form expressing agreement to participate in the study was obtained from each student. Finally, students were informed they were under no obligation to continue with the study, and that they were free to stop participating in the study whenever they chose to do so.

\subsection{The Survey Instrument}

A number of research instruments were used to investigate strategic reading including survey data based on self-reports of strategy use. For example, the "survey of reading strategies" (SORS) was developed by Mokhtari and Sheorey (2002) for adolescent and adult ESL students. The instrument actually used in this study was the MARSI which is one of the most widely-used instruments in reading strategy research. The MARSI was developed by Mokhtari and Reichard (2002) to measure readers' metacognitive awareness and control of strategic processes. In an effort to help researchers study metacognitive awareness of reading strategies, Mokhtari and Reichard (2002), the authors of the 30-item survey, divided metacognitive reading strategies into three factors or subscales. The first subscale was global reading strategies which consisted of 13 items and contained reading strategies that help the reader emerge with a global analysis of a text. According to Mokhtari and Reichard (2002), global strategies can be thought of as "generalized, intentional reading strategies aimed at setting the stage for the reading act" (e.g., setting purpose for reading or making predictions) (p. 252). Global strategies included planning, monitoring, and evaluating what one has read. The second subscale was problem-solving strategies which consisted of 8 items and involved reading strategies aimed at solving problems when the text becomes difficult to read. According to Mokhtari and Reichard (2002), problem-solving strategies are "localized, focused problem-solving or repair strategies used when problems develop in understanding textual information (e.g., checking one's understanding on encountering conflicting information or re-reading for better understanding)" (p. 252). The third subscale was support or functional strategies and consisted of 9 items (e.g., underlining unknown words or using dictionaries) to support sustained responses to reading and facilitate reading comprehension.

\subsection{Data Collection}

In order to identify the range of metacognitive reading strategies among Kuwaiti EFL college students, data collection was focused in its first stage on uploading the MARSI survey to elicit participants' responses online. The survey items were encoded by the researchers on Google Forms for easy access through the students' mobile phones. From February to July, 2018, the survey was made available online for the students. Out of a total of 83 students, there were 3 non-respondents to the survey, and the respondent rate was $96.39 \%$ which resulted in a total of 80 respondents who became the study sample.

\subsection{Data Analysis}

In order to identify the study participants' range of metacognitive reading strategies, data analysis first focused on calculating each scored survey item by adding up the cumulative numbers for each student. After the entire items of the survey were scored, the points for each of the reading strategies items were totaled for each participating student. This step was made possible by utilizing the Microsoft Excel software program. Excel was also used to generate the means, standard deviations, and ranks for each of the metacognitive reading strategies of the participating students as a whole group in terms of the students' overall strategy use. Percentages of three categories of global, problem-solving, and support strategy users (high=3.50-5.00; medium=2.50-3.49; low $=1.00-2.49$ ) were counted and the total MARSI percentages were calculated to further clarify the participating students' overall strategy use. Table 1 displayed the participating students' metacognitive reading strategies. Subsequently, data analysis focused on comparing the two subgroups of the participating students (i.e., BSN and ADN) by incorporating means, standard deviations, and ranks for each subgroup in order to highlight their variations in strategy use. Table 2 displayed a comparison of strategy use between the BSN and ADN students. Finally, data analysis identified the most and the least frequently used reading strategies based on the total scores within each of the categories of global, problem-solving, and support strategies. Furthermore, the most and the least frequently-used strategies were identified based on the ranks and means of each strategy. Table 3 displayed the most and the least frequently-used strategies employed by the participating students as a whole group.

\section{Results}

The results of the survey provided a general view into the types of metacognitive reading strategies employed by the EFL students at the College of Nursing in Kuwait which included global, problem-solving, and support strategies. Table 1 displayed the types of metacognitive reading strategies used by the participating students. The 
results also indicated variations in strategy use between the students at the BSN and ADN programs. Table 2 showed that the BSN students employed reading strategies more frequently than the ADN students. The contextual factor (i.e., years of studying English) was found to partially explain the BSN students' advantages in strategy use. Finally, the data analysis identified the 10 most and the 10 least frequently-used categories of metacognitive reading strategies by the Kuwaiti students as a whole group. Table 3 displayed the most and the least frequently used categories of metacognitive reading strategies among the participating students.

\subsection{The Types of Metacognitive Reading Strategies}

The first research question sought information about the types of metacognitive reading strategy use among the participants. Table 1 displayed the participating students' metacognitive awareness of reading strategies, and provided the means, standard deviations, percentages, and ranks for each type of the metacognitive reading strategies. The descriptive statistics were generated from the MARSI to help understand students' metacognitive awareness and strategy use while reading texts.

Table 1. Metacognitive awareness of reading strategies by the College of Nursing students in Kuwait

\begin{tabular}{|c|c|c|c|c|c|c|}
\hline \multirow{2}{*}{ Strategy Type } & \multicolumn{3}{|c|}{ Categories } & \multirow{2}{*}{$M$} & \multirow{2}{*}{$S D$} & \multirow{2}{*}{ Rank } \\
\hline & High & Medium & Low & & & \\
\hline GLOB & $71.25 \%$ & $22.50 \%$ & $6.25 \%$ & 3.79 & 0.62 & 2 \\
\hline PROB & $82.50 \%$ & $13.75 \%$ & $3.75 \%$ & 4.00 & 0.74 & 1 \\
\hline SUP & $45.00 \%$ & $37.25 \%$ & $17.75 \%$ & 3.45 & 0.81 & 3 \\
\hline MARSI & $72.50 \%$ & $26.25 \%$ & $1.25 \%$ & 3.77 & 0.62 & - \\
\hline
\end{tabular}

Note. MARSI=metacognitive awareness of reading strategies inventory; GLOB=global strategies; PROB=problem-solving strategies; $\mathrm{SUP}=$ support strategies; High use $(\mathrm{M}=3.50-5.00)$; Medium use $(\mathrm{M}=2.50-3.49)$; Low use $(\mathrm{M}=1.00-2.49)$.

Employing standards developed by Mokhtari and Reichard (2002) as criteria for labelling high, medium, and low users, table 1 revealed that the participants' overall strategy use was high $(\mathrm{M}=3.77, \mathrm{SD}=0.62)$. Moreover, the participating students were high frequency strategy users who also employed a wide range of reading strategies as follows: $72.50 \%$ high users, $26.25 \%$ medium users, and only $1.25 \%$ low users. The most frequently-used strategies were problem-solving strategies $(\mathrm{M}=4.00, \mathrm{SD}=0.74)$, with $82.50 \%$ high users, $13.75 \%$ medium users, and $3.75 \%$ low users respectively. Following the highest frequency of problem-solving strategy use, the students also showed a preference for employing global strategies while reading $(\mathrm{M}=3.79, \mathrm{SD}=0.62) .71 .25 \%$ of the students were high users of problem-solving strategies, followed by $22.50 \%$ medium users and $6.25 \%$ low users respectively. The least frequently-used strategies that the students employed were support strategies $(\mathrm{M}=3.45$, $\mathrm{SD}=0.81$ ). While $45 \%$ of the participants were high users of support strategies, more than half of the students did not show a strong preference for using support strategies, with 37.25 medium users and $17.75 \%$ low users respectively.

\subsection{Variations in Strategy Use Between the BSN and ADN Students}

The second research question requested data on the variations in strategy use between the BSN and ADN students. Table 2 displayed the disparity in strategy use between the BSN and ADN students in the means, standard deviations, and ranks for each type of the metacognitive reading strategies.

Table 2. A comparison of strategy use between the BSN and ADN students

\begin{tabular}{lccccccccc}
\hline \multirow{2}{*}{ Strategy Use } & \multicolumn{3}{c}{ Whole Group } & \multicolumn{3}{c}{ BSN Students } & \multicolumn{3}{c}{ ADN Students } \\
\cline { 2 - 10 } & $M$ & $S D$ & Rank & $M$ & $S D$ & Rank & $M$ & $S D$ & Rank \\
\hline GLOB & 3.79 & 0.62 & {$[2]$} & 3.97 & 0.54 & {$[2]$} & 3.55 & 0.64 & {$[2]$} \\
PROB & 4.00 & 0.74 & {$[1]$} & 4.11 & 0.57 & {$[1]$} & 3.85 & 0.88 & {$[1]$} \\
SUP & 3.45 & 0.81 & {$[3]$} & 3.53 & 0.77 & {$[3]$} & 3.37 & 0.83 & {$[3]$} \\
MARSI & 3.77 & 0.62 & - & 3.92 & 0.53 & - & 3.58 & 0.67 & - \\
\hline
\end{tabular}

Note. MARSI=metacognitive awareness of reading strategies inventory; GLOB=global strategies; $\mathrm{PROB}=$ problem-solving strategies; $\mathrm{SUP}=$ support strategies; High use $(\mathrm{M}=3.50-5.00)$; Medium use $(\mathrm{M}=2.50-3.49)$; Low use $(\mathrm{M}=1.00-2.49)$.

Data analysis revealed that there exists a consistency in overall strategy use in each type of metacognitive reading strategy between the participating students as a whole group as well as the two subgroups of the BSN and ADN programs. First, both the BSN and ADN students were high users of overall metacognitive reading strategies, 
which is consistent with the group's overall strategy use. Both the BSN students were overall high users of metacognitive reading strategies $(M=3.92, S D=0.53)$, and the $A D N$ students were high users as well $(M=3.58$, $\mathrm{SD}=0.67$ ). The results indicated, however, that the BSN students used the totality of metacognitive reading strategies more frequently than the ADN students.

Second, consistent with the results of each strategy use as a whole group, both the BSN students and ADN students favored problem-solving strategies the most, followed by global strategies which ranked the second, and support strategies which ranked the third. As a group, the students were high users of both problem-solving and global strategies with mean scores of $(\mathrm{M}=4.00 ; \mathrm{M}=3.79)$ respectively; however, they were medium users of support strategies $(\mathrm{M}=3.45)$. Table 2 showed that the students at the BSN program used problem-solving strategies most frequently $(M=4.11, S D=0.57)$, followed by global strategies $(M=3.97, S D=0.54)$, but they used support strategies least frequently $(\mathrm{M}=3.53, \mathrm{SD}=0.77)$. While the $\mathrm{BSN}$ students were high users of problem-solving, global and support strategies, the ADN students were shown as high users of problem-solving strategies $(\mathrm{M}=3.85, \mathrm{SD}=0.88)$ and global strategies $(\mathrm{M}=3.55, \mathrm{SD}=0.64)$, and medium users of support strategies $(\mathrm{M}=3.37, \mathrm{SD}=0.83)$. Overall, the analysis revealed variations in strategy use between the BSN and ADN students in that the BSN students employed a wider range of strategies and used them more frequently than the ADN students. Years of studying English, therefore, might partly account for this disparity between the two groups.

\subsection{The Most vs. the Least Frequently-Used Strategies}

Data analysis established the most and the least frequently-used strategies by the participants. While 5 out of 8 categories of problem-solving strategies were identified as the most frequently- used strategies, 6 out of 9 categories of support strategies were identified as the least frequently-used strategies by the students. Table 3 presented the most and the least frequently-used metacognitive reading strategies employed by the students to highlight their choices of strategy use.

Table 3. The most and least frequently-used metacognitive reading strategies employed by the participants

\begin{tabular}{lllll}
\hline Strategy Use & Inventory Items & Mean & SD & Rank \\
\hline & The Most Frequently Used Categories of Reading Strategies & & \\
PROB & Pay closer attention to my reading when text becomes difficult. & 4.34 & 1.04 & 1 \\
PROB & Re-read to increase my understanding of difficult texts. & 4.26 & 1.02 & 2 \\
PROB & Try to get back on track when I lose concentration. & 4.18 & 1.06 & 3 \\
PROB & Adjust my reading speed according to what I'm reading. & 4.15 & 0.97 & 4 \\
GLOB & Think about what I know to help me understand what I read. & 4.10 & 0.99 & 5 \\
SUP & Underline or circle information in the text to remember it. & 4.05 & 1.09 & 6 \\
GLOB & Have a purpose in mind when I read. & 4.03 & 1.02 & 7 \\
PROB & Read slowly but carefully to understand what I'm reading. & 4.00 & 1.13 & 8 \\
GLOB & Check my understanding of conflicting information in the text. & 3.94 & 1.01 & 9 \\
GLOB & Think about whether the text content fits my reading purpose. & 3.89 & 1.11 & 10 \\
\hline & The Least frequently Used Categories of Reading Strategies & & & \\
SUP & Read aloud to help me understand what I read the difficult text. & 3.13 & 1.39 & 1 \\
SUP & Take notes while reading to help me understand what I read. & 3.34 & 1.35 & 2 \\
SUP & Summarize the reading to reflect on important text information. & 3.38 & 1.31 & 3 \\
SUP & Ask myself questions I like to have answered in the text. & 3.40 & 1.40 & 4 \\
SUP & Discuss what I read with others to check my understanding. & 3.41 & 1.17 & 5 \\
PROB & Stop from time to time and think about what I'm reading & 3.44 & 1.27 & 6 \\
GLOB & Critically analyze and evaluate the information in the text. & 3.55 & 1.09 & 7 \\
GLOB & Use tables, figures, or pictures in text to increase understanding & 3.56 & 1.22 & 8 \\
SUP & Go back and forth in the text to find relationships among ideas. & 3.68 & 1.05 & 9 \\
GLOB & Use context clues to help me better understand my reading. & 3.70 & 1.17 & 10 \\
\hline
\end{tabular}

Note. $\mathrm{MARSI}=$ metacognitive awareness of reading strategies inventory; $\mathrm{GLOB}=$ global strategies; $\mathrm{PROB}=$ problem-solving strategies; $\mathrm{SUP}=$ support strategies.

Data analysis revealed that 5 problem-solving strategies were the most frequently-used metacognitive reading strategies by the participating students, followed by 4 global strategies and 1 support strategy. Problem-solving strategies were used as "action plans" (Mokhtari \& Reichard, 2002) or repair strategies to tackle problems when confronting any difficulties in reading. Table 3 showed that the students had strong preferences for problem-solving strategies, with 5 out of 8 categories (62.5\%) of problem-solving strategies chosen as their most 
frequently- used reading strategies. This meant that when confronted with reading difficulties, the students preferred to utilize $62.5 \%$ of categories of the problem-solving strategies to pay closer attention to the text $(\mathrm{M}=$ $4.34, \mathrm{SD}=1.04)$, re-read the text $(\mathrm{M}=4.26, \mathrm{SD}=1.02)$, get back on track when losing concentration $(\mathrm{M}=4.18$, $\mathrm{SD}=1.06)$, adjust reading speed $(\mathrm{M}=4.15, \mathrm{SD}=0.97)$, and read slowly but carefully to understand the text $(\mathrm{M}=4.00, \mathrm{SD}=1.13)$.

Table 3 showed the students' preferences for using global strategies, with 4 out of 13 categories $(30.77 \%)$ of global strategies chosen as their second most frequently used reading strategies. Global strategies were used to have a general analysis of text or setting a purpose for reading (Mokhtari \& Reichard, 2002). This meant that the participants adopted global strategies to orient themselves to the reading task. Moreover, the students utilized $30.77 \%$ of global strategies to think about what they know $(\mathrm{M}=4.10, \mathrm{SD}=0.99)$, have a reading purpose in mind $(\mathrm{M}=4.03, \mathrm{SD}=1.02)$, check their understanding of conflicting information $(\mathrm{M}=3.94, \mathrm{SD}=1.01)$, and think about whether the content fits the reading purpose $(\mathrm{M}=3.89, \mathrm{SD}=1.11)$.

Table 3 indicated that the students used only 1 out of 9 categories (11.11\%) of support strategies as their third most frequently used strategy. Support strategies served as functional or practical mechanisms to facilitate the reading process (Mokhtari \& Reichard, 2002). This meant that they adopted a single support strategy to underline or circle information in the text while reading $(\mathrm{M}=4.05, \mathrm{SD}=1.09)$.

With regard to the least frequently used categories of metacognitive reading strategies, data analysis also revealed that 6 support strategies were the least frequently-used strategies by the students, followed by 3 global strategies and 1 problem-solving strategy. In Table 3 , the students chose support strategies as the least frequently used strategies in reading, with 6 out of 9 categories $(66.67 \%)$ of support strategies. The results indicated that the students utilized $66.67 \%$ of support strategies infrequently as a functional strategy to facilitate the reading process. In other words, the students used support strategies infrequently, including reading aloud when reading difficult texts $(\mathrm{M}=3.13, \mathrm{SD}=1.39)$, taking notes while reading $(\mathrm{M}=3.34, \mathrm{SD}=1.35)$, summarizing the text $(\mathrm{M}=3.38, \mathrm{SD}=1.31)$, asking questions in the text $(\mathrm{M}=3.40, \mathrm{SD}=1.40)$, discussing the reading with others $(\mathrm{M}=3.41, \mathrm{SD}=1.17)$, and going back and forth in the text to find relationships among ideas $(\mathrm{M}=3.68, \mathrm{SD}=1.05)$.

Table 3 also showed that the students used 3 global strategies least frequently, with 3 out of 8 categories (23.08\%) of global strategies. Global strategies included critically analyzing and evaluating the text information $(\mathrm{M}=3.55$, $\mathrm{SD}=1.09)$, using tables or pictures in text $(\mathrm{M}=3.56, \mathrm{SD}=1.22)$, and using context clues $(\mathrm{M}=3.70, \mathrm{SD}=1.17)$. Moreover, Table 3 also indicated that the students reported using a single category of problem solving strategies least frequently, with 1 out of 8 categories $(12.50 \%)$ of problem solving strategies. The problem-solving strategy was to stop from time to time and think about the reading $(\mathrm{M}=3.44, \mathrm{SD}=1.27)$.

\subsection{Conclusions}

Data analysis resulted in the following conclusions. First, the data indicated that $72.50 \%$ of the EFL students at the College of Nursing in Kuwait were high users of problem-solving and global strategies, and medium users of support strategies. More specifically, $82.50 \%$ of the participants were high users of the problem-solving strategies, and $70.25 \%$ of the participants were high users of global strategies. However, the results also showed that $55 \%$ of the participants were low to medium users of support strategies. Second, the analysis revealed a consistent pattern of strategy use between the participating students as a whole group as well as the BSN and ADN students. Similar to the group's overall strategy use, both the BSN and ADN students were high users of overall metacognitive reading strategies. However, the BSN students $(\mathrm{M}=3.92)$ used overall metacognitive reading strategies more frequently than the $\mathrm{ADN}$ students $(\mathrm{M}=3.58)$. Third, in terms of rankings of the types of metacognitive reading strategies, the participants as a group as well as both the BSN students and ADN students preferred to use problem-solving strategies the most, followed by global strategies, and support strategies which ranked the third. However, the data also revealed variations in the frequency of strategy use between the BSN and ADN students. While the BSN students were high users of problem-solving, global and support strategies, the ADN students were high users of problem-solving strategies and global strategies, and medium users of support strategies. Fourth, the results also showed that while 5 out of 8 categories of problem-solving strategies were identified as the most frequently-used strategies, 6 out of 9 categories of support strategies were identified as the least frequently-used strategies by the participating students. This meant that the participants showed a preference for $62.5 \%$ of problem-solving strategies to tackle problems when confronting any difficulties in reading. Subsequently, the participants preferred to use $30.77 \%$ of global strategies as their second most frequently-used strategy to orient themselves to reading texts. The participants only chose $11.11 \%$ of support strategies (i.e., underline or circle information in the text while reading) as their only support strategy to facilitate the reading process. As for the least frequently used strategies, the students utilized $66.67 \%$ of support strategies 
least frequently as a functional strategy to facilitate the reading process, followed by $23.08 \%$ of global strategies (e.g., critically analyze the reading text), and $12.50 \%$ of problem-solving strategies (i.e., stop from time to time and think what I'm reading).

\section{Discussion}

The findings of the study indicated that the participating students were high users of both the problem-solving and the global strategies, and they were medium users of support strategies when they read academic texts in their major field of study. The high use of problem-solving and global strategies can be attributed to student awareness of metacognitive reading strategies that can assist them in reading comprehension. A combination of English medium instruction (EMI) in all their major courses at the college and the focus on medical content in English classes have probably contributed to a learning environment that provided sustained contact with the English language. The rich exposure to English also provided ample linguistic input for the students that enhanced their reading skills and increased their comprehension of medical texts. The general result of the study is consistent with the general findings of previous research studies on EEL learners' high overall strategy use in Oman (Al-Mekhlafi, 2018), the United Arab Emirates (Endley, 2016), and Bahrain (Malcom, 2009). These studies suggested that the high use of metacognitive reading strategies depends to some degree on the language learners' educational contexts. A common denominator shared between these institutes of higher education in the Gulf is that they all employ English as a medium of instruction. The respondents in Al-Mekhlafi (2018), Endley (2016), and Malcom (2009) were from universities where they regularly received ample exposure to the English language on a daily basis. As students in an EMI college, the participants in the present study were stimulated by their learning context to develop their overall proficiency in English including their ability to read efficiently. Thus, it is to be anticipated that they will have fewer language learning barriers when compared to respondents who receive most of their learning in their L1 (Arabic). However, this general result of the study about respondents being high users of problem-solving and global strategies is not consistent with the general findings of previous research studies showing EFL respondents' moderate awareness and use of metacognitive reading strategies (e.g., Al-Sohbani, 2014; Boyraz \& Altinsoy, 2017; Meniado, 2016). The moderate strategy use can be explained by the students' limited exposure to English on a daily basis which has probably contributed to their lack of awareness of metacognitive reading strategies that can facilitate their reading comprehension.

Metacognitive reading strategies were grouped in the present study according to the three types of global, problem-solving, and support strategies. Each of the three types subsumed a set of categories. After respondents answered the metacognitive reading strategies survey, the analysis revealed that their most frequently-used strategies were problem-solving strategies. This finding is consistent with most studies that investigated EFL students' metacognitive strategy use. In fact, one of the most consistent findings on metacognitive strategy use is that EFL learners from various native language backgrounds prefer the use of problem-solving strategies over other strategies to resolve their reading difficulties. This result also supports findings by Al-Mekhlafi (2018), Al-Sohbani (2013), and Meniado (2016) having Arabic-speaking students in Saudi-Arabia, Yemen, and Oman actively using problem-solving strategies at a high level in EFL. In Turkey, Boyraz and Altinsoy (2017) also reported that students actively used problem-solving strategies to cope with reading academic texts in English. This finding showed that problem-solving strategies are a shared feature of EFL learners at different levels of proficiency in different EFL contexts.

In terms of the finding on the variation between BSN and ADN in strategy use, the analysis revealed that due to the fact that the four-year BSN students had more years of studying English than the two-year ADN students, they developed in their use and manipulation of reading strategies to comprehend English academic texts. No studies of metacognitive reading strategies have controlled for the variable of duration of English language study. However, other studies of EFL learners' learning strategies have controlled for the variable of duration of English language study. While Alhaysony (2017) reported a positive correlation between the duration of English study and the frequency of use of language learning strategies among Saudi EFL students, Magno (2010) has also established a positive relationship between duration of English language study and Korean EFL students' use of learning strategies.

\section{Implications for Pedagogy}

The present study employed MARSI as an instrument to identify the metacognitive reading strategies used by EFL students at the College of Nursing in Kuwait. Presumably, the students used these strategies to overcome the difficulties they faced while reading English academic texts. The data analysis revealed that the participating students were using a varied repertoire of reading strategies. The data also revealed that none of the participants utilized the full range of strategies in MARSI. The findings suggested that the participants had an adequate 
command of these strategies but also revealed that they could be developed further to utilize the full range of metacognitive reading strategies. There was also variation among the BSN and ADN participants in relation to the duration of English language study which might have had an impact on BSN students' ability to make more efficient use of reading strategies. This finding also suggested the need for instruction in the strategies that were not fully utilized by the students. Therefore, the question related to the most frequently-used and the least frequently-used strategies was of particular relevance to teaching. For example, it is worth mentioning that of all the support strategies, the most frequently-used support strategy was underlining key words and phrases. The participants reported a lack of use of some other equally important support strategies such as consulting dictionaries, note-taking, summarizing, reflecting through asking questions, and discussing the reading with others. The recommendation that emerges from this study is that it is necessary to first identify the needs of the students through the MARSI or any other comparable instrument. Efficient pedagogical intervention can then be focused on the least frequently-used strategies by the students. The study showed that the participating students preferred to use problem-solving and global strategies over support strategies. In this case, instruction can foreground support strategies and then global strategies followed by problem-solving strategies.

\section{Implications for Research}

Due to the fact that no published research studies have been conducted in Kuwait on students' awareness of metacognitive reading strategies, there is a need for more research on the awareness and use of metacognitive reading strategies among Kuwaiti students through all stages of the Kuwaiti educational system. Strategy instruction studies are also needed in Kuwait through administering such instruments as MARSI (Mokhtari \& Reichard, 2002) and SORS (Mokhtari \& Sheorey, 2002). In order to be equipped with adequate knowledge about learner needs, strategy instruction studies, however, should be evidence-based regarding student needs as well as their awareness and use of metacognitive reading strategies.

\section{References}

Ahmadi, Q. S. (2017). Unwelcome? English as a medium of instruction (EMI) in the Arabian Gulf. English Language Teaching, 10(8), 11-17. https://dx.doi.org/10.5539/elt.v10n8p11

Alhaysony, M. (2017). Language learning strategies use by Saudi EFL students: The effect of duration of English language study and gender. Theory and Practice in Language Studies, 7(1), 18-28. https://dx.doi.org/10.17507/tpls.0701.03

Al-Mekhlafi, A. M. (2018). EFL learners' metacognitive awareness of reading strategies. International Journal of Instruction, 11(2), 297-308. https://dx.doi.org/10.12973/iji.2018.11220a

Alotaibi, A. M., Aldaihani, H. A., \& Alrabah, S. (2014). An investigation of the factors which contribute to low English achievement in secondary schools, as perceived by Kuwaiti and non-Kuwaiti English teachers. European Scientific Journal, ESJ, 10(25), 440-459.

Al-Sohbani, Y. (2013). Metacognitive reading strategies use by Yemeni EFL undergraduate university students. Frontiers of Language and Teaching, 4, 121-133.

Boyraz, S., \& Altinsoy, E. (2017). Metacognitive awareness of reading strategies in EFL context. International Journal of Language Academy, 5(5), 159-167. https://dx.doi.org/10.18033/ijla.3655

Endley, M. J. (2016). Proficiency as a variable in Gulf EFL students' employment of reading strategies. Reading in a Foreign Language, 28(2), 183-223.

Ferguson, G. (2013). English for medical purposes. In B. Paltridge \& S. Starfield (Eds.), The handbook of English for specific purposes (pp. 243- 262). Malden, MA: John Wiley \& Sons, Inc.

Friesen, D. C., \& Haigh, C. A. (2018). How and why strategy instruction can improve second language reading comprehension: A review. The Reading Matrix: An International Online Journal, 18(1), 1-18.

Huang, J., \& Nisbet, D. (2014). The relationship between reading proficiency and reading strategy use: A study of adult ESL learners. Journal of Adult Education, 43(2), 1-11.

Magno, C. (2010). Korean students' language learning strategies and years of studying English as predictors of proficiency in English. TESOL Journal, 2, 39-61.

Malcolm, D. (2009). Reading strategy awareness of Arabic-speaking medical students studying in English. System, 37(4), 640-651. https://doi.org/10.1016/j.system.2009.09.008

Mehrdad, A. G., Ahghar, M. R., \& Ahghar, M. (2012). The effect of teaching cognitive and metacognitive strategies on EFL students' reading comprehension across proficiency levels. Procedia- Social and 
Behavioral Sciences, 46, 3757-3763. https://dx.doi.org/10.1016/j.sbspro.2012.06.142

Meniado, J. C. (2016). Metacognitive reading strategies, motivation, and reading comprehension performance of Saudi EFL students. English Language Teaching, 9(3), 117-129. https://dx.doi.org/10.5539/elt.v9n3p117

Mintz, E., \& Yun, J. T. (1999). The complex world of teaching perspectives from theory and practice. Cambridge, MA: Harvard Education Press.

Mokhtari, K., \& Reichard, C. A. (2002). Assessing students' metacognitive awareness of reading strategies. Journal of Educational Psychology, 94(2), 249-259. https://doi.org/ 10.1037//0022-0663.94.2.249

Mokhtari, K., \& Sheorey, R. (2002). Measuring ESL students' awareness of reading strategies. Journal of Developmental Education, 25(3), 2-11.

Pani, S. (2004). Reading strategy instruction through mental modelling. ELT Journal, 58(4), 355-362. https://doi.org/10.1093/elt/58.4.355

Park, J. (2015). Insights into Korean EFL Students' Reading Motivation, Proficiency, and Strategy Use. English Teaching, 70(1), 57-74. https://doi.org/ 10.15858/engtea.70.1.201503.57

Patton, M. Q. (2015). Qualitative research and evaluation methods (4th ed.). Thousand Oaks, CA: Sage.

Pei, L. (2014). Does metacognitive strategy instruction indeed improve Chinese EFL learners' reading comprehension performance and metacognitive awareness? Journal of Language Teaching and Research, 5(5), 1147-1152. https://dx.doi.org/10.4304/jltr.5.5.1147-1152

Pienemann, M. (Ed.). (2005). Cross-linguistic aspects of processability theory. Philadelphia, PA: John Benjamins Publishing.

\section{Copyrights}

Copyright for this article is retained by the author, with first publication rights granted to the journal.

This is an open-access article distributed under the terms and conditions of the Creative Commons Attribution license (http://creativecommons.org/licenses/by/4.0/). 